\title{
Aircraft-based observations of isoprene epoxydiol-derived secondary organic aerosol (IEPOX-SOA) in the tropical upper troposphere over the Amazon region
}

Christiane Schulz et. al

Correspondence to: Johannes Schneider (johannes.schneider@mpic.de) 


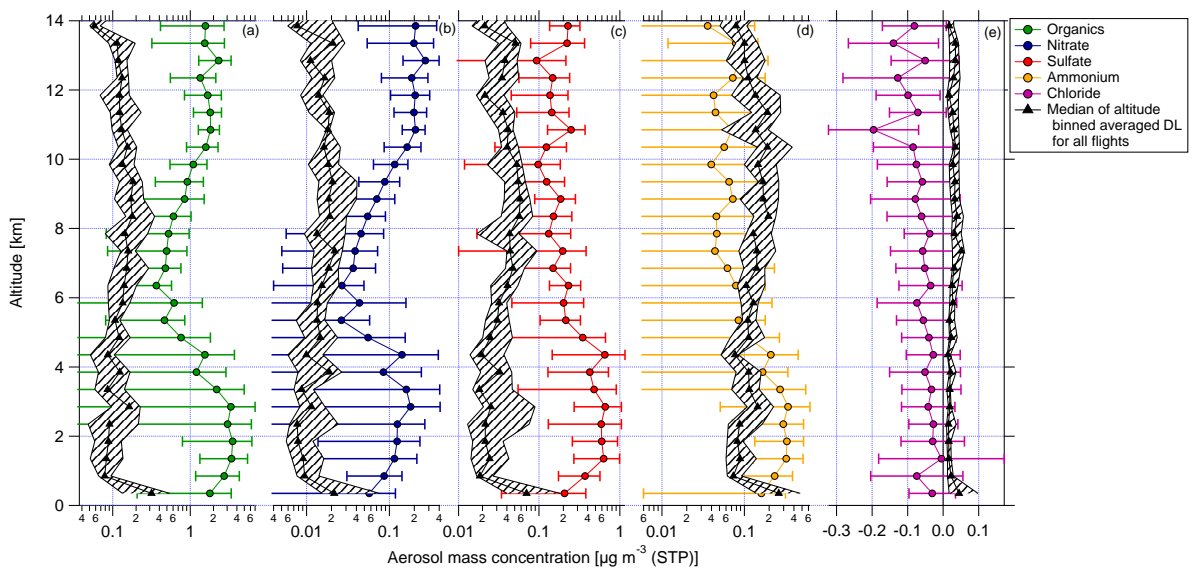

Figure S1. Vertical profile of averaged mass concentrations and median of altitude binned averaged detection limits for (a) organics, (b) nitrate, (c) sulfate, (d) ammonium and (e) chloride for all flights during the ACRIDICON-CHUVA campaign. Mass concentration axes are logarithmic, except for chloride. Chloride is not considered in the analysis, because measured data are below the detection limit. Detection limits were derived by averaging time-dependent detection limit values per altitude bin for each flight. The median of the altitude binned averaged detection limits for all flights is given in this plot. 


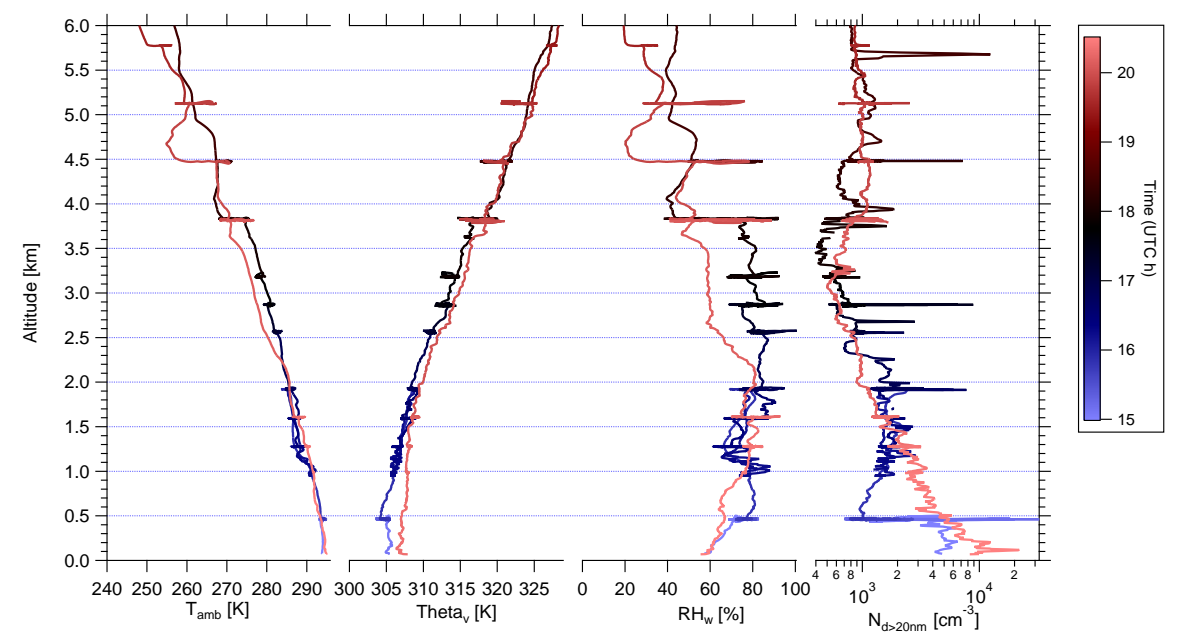

Figure S2. Vertical profile of (a) ambient temperature $\left(T_{\mathrm{amb}}\right)$, (b) virtual potential temperature $\left(\Theta_{\mathrm{v}}\right)$, (c) relative humidity with respect to

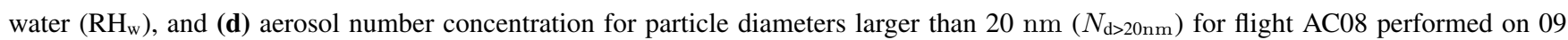
September 2014. The boundary layer height was determined by evaluating these parameters. The daily evolution is visible in the data with BL height of $\approx 1 \mathrm{~km}$ before noon (local time) and increasing BL height up to $\approx 2 \mathrm{~km}$ in the afternoon (local time). Time is given in UTC hours. The discrepancy to local time is - 4 hours. 


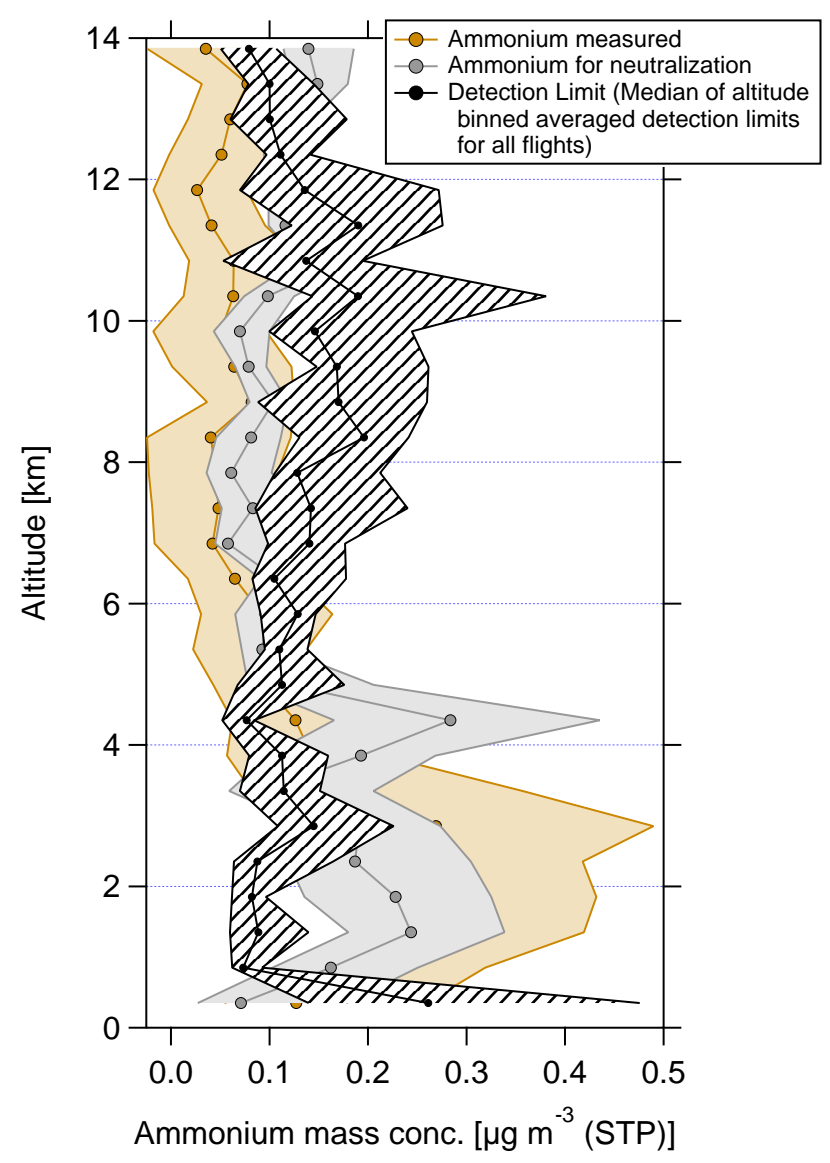

Figure S3. Vertical profile of measured (yellow), for neutralization needed ammonium (grey), and the ammonium detection limit (black). Aerosol in the LT was mainly neutralized, aerosol in the UT was mainly acidic regarding inorganic species. Please note, that differences between measured and calculated ammonium could derive from uncertainties due to cross-relations between ammonium and water fragmentation table entries. Detection limit was derived by averaging time-dependent detection limit values per altitude bin for each flight. The median of the altitude binned averaged detection limits for all flights is given in this plot. 